\title{
Comparison of Three-phase Active Rectifier Solutions for Avionic Applications: Impact of the Avionic Standard DO-160 F and Failure Modes
}

\author{
U. Borović, S. Zhao, M. Silva, Y. E. Bouvie, M. Vasić, J. A. Oliver, P. Alou, J. A. Cobos, \\ F. Árevalo, J.C. García-Tembleque, J.Carmena, C. García, P. Pejović
}

\section{INTRODUCTION}

In the ever-growing market of the civil aircraft, there has been a constant need for improvement in many fields. The current trend is mainly oriented into replacing heavy and maintenance costly hydraulic, pneumatic and mechanical parts of the aircraft with electrical equivalents. Any part of the airborne aircraft must not fail during the flight, which gives the reliability of the equipment the utmost importance. Moreover, the take-off weight of the aircraft is of major concern due to the increased fuel consumption. Thus, the main concerns in the aircraft, the reliability, weight and volume will be the major design constraints in this work.

The conventional rectifiers employed in nowaday aircraft are relying on the passive solutions which are extremely robust, but heavy and require tight mains regulation in order to operate within specifications [1], [2].

The twelve-pulse three-phase voltage loaded rectifier is one of the typical representative of the auto-transformer based rectifiers. The basic operation of the rectifier, as well as design guidelines for the line side interphase transformer is presented in [3]. The presented rectifier provides high reliability due to the line commutating diode bridges and high efficiency due to the fact that no high-frequency switching is employed. However, apart from line filtering inductors, the interphase transformers are key part of the rectifier which increments the total weight. Without adding an active stage at the output [4], no control over the output voltage is possible.

The active rectifiers utilize semiconductors switching at high frequencies in order to provide control to the rectifier input currents and output voltage, and thus creating an opportunity to reduce size of magnetic components.

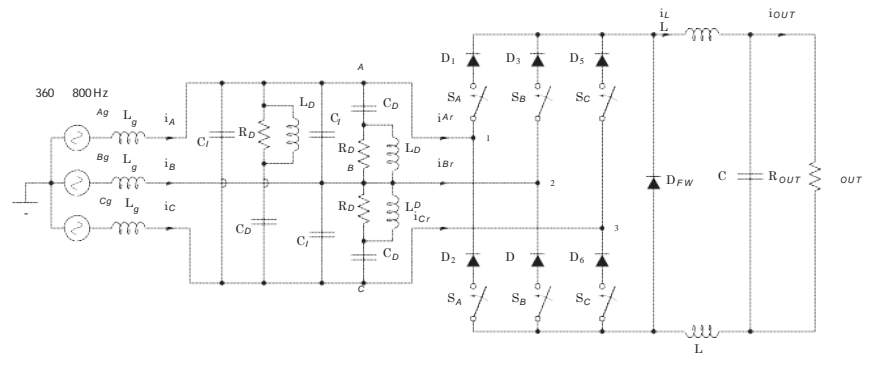

Figure 1. The three-phase Buck rectifier

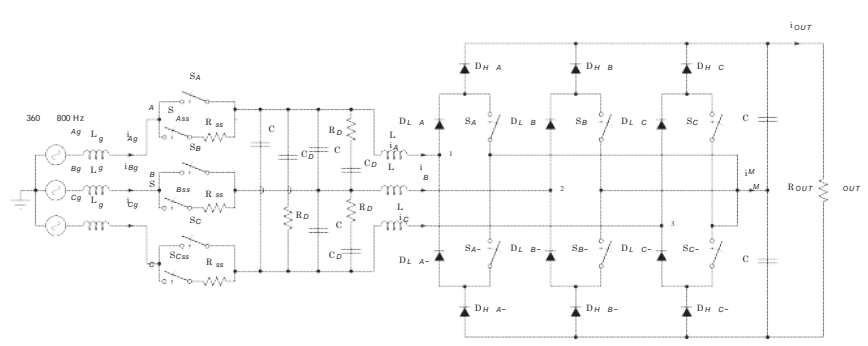

Figure 2. The three-phase Vienna rectifier with soft start relays and additional relays needed to meet failure requirements

The reliability of the high-frequency switching devices can be argued, but with the advancements in technology, more robust and reliable switching devices are becoming available in the market.

This research work as well as the specifications of the converter are developed under the Clean Sky European program in collaboration with Indra Sistemas ${ }^{\mathrm{TM}}$.

In [5] an extensive and thorough analysis has been carried out comparing several Boost type three-phase AC/DC converters at input voltage $115 \mathrm{~V}_{\mathrm{AC}}, 400-800 \mathrm{~Hz}$ and output 
power of $5 \mathrm{~kW}$. In it has been shown that the future threephase rectifier designs are advantageous with respect to the passive multi-pulse counterparts given the current technology progress in the industry.

In this work, the three-phase converter is designed for $28 \mathrm{~V}_{\text {DC }}$ output voltage and $10 \mathrm{~kW}$ constant power load $\left(P_{\mathrm{OUT}}\right)$. The approach that is used in this application is an active three-phase rectifier which provides the intermediate DC bus, followed by a DC/DC converter which adjusts the bus voltage level to $28 \mathrm{~V}_{\mathrm{DC}}$ providing $360 \mathrm{~A}_{\mathrm{DC}}$.

The main contribution of this paper is to extend the analysis of previous comparisons focused on weight, size and efficiency [5] analyzing the impact of the specific points of the DO-160 F standard on the rectifier and to investigate what implications arise when failure modes are taken into consideration. The comparative study will be addressed on three candidates for the $10 \mathrm{~kW}$ three-phase rectifier solution.

\section{AnAlyzed Topologies}

The three-phase Boost rectifier [6]-[8] is a typical representative of the two-level voltage source converter. Its main constraint is that the DC bus voltage needs to be sufficiently higher than maximum line to line voltage of the three-phase source. Furthermore, this converter is also bidirectional which will be reflected on its superior reactive power compensation capabilities. The control of the input current quality is realized by controlling the applied voltage to the input inductors $L$. The presence of the inductors on the $\mathrm{AC}$ side implies relatively high weight due to two-level nature of the rectifier [9]. However, AC inductors are beneficial for EMI filtering capacitor size, which implies less reactive power handling by the rectifier. Additionally, this topology and its derivations require circuitry for the soft start-up.

The three-phase Buck rectifier [10]-[12] is presented in Figure 1. The first main constraint of this three-level current source converter is that DC bus voltage needs to be sufficiently lower than maximum line to line voltage of the three-phase source. Due to the presence of the series diodes, this topology has unidirectional power flow which will restrict the amount of reactive power that can be handled by the rectifier. Basic operation of the rectifier consists on driving the switches in such a way so that generated sinusoidal fundamental phase currents at the input are in phase with the corresponding phase voltages. The generation of currents at AC side utilizes DC link inductor current along with Current Space Vector Modulation (CSVM). The main advantage of this rectifier topology is that inductive filtering is moved to the DC side and thus provides the ability to reduce weight of the inductor with respect to the Boost case. Moreover, this rectifier is not sensitive to the shoot through failure of the leg unlike the Boost. Also, soft start circuitry is not needed. However, it requires relatively large input capacitors which will further increase the reactive power that needs to be compensated by the converter.

The three-phase Vienna rectifier [13]-[15] is presented in Figure 2. The Vienna rectifier keeps all general advantages with the respect to the Boost rectifier with exception that it is unidirectional converter which implies limitations regarding reactive power handling. However, due to the presence of the inductor on the AC side the EMI capacitor needed to comply with the harmonic requirements is small. Moreover,

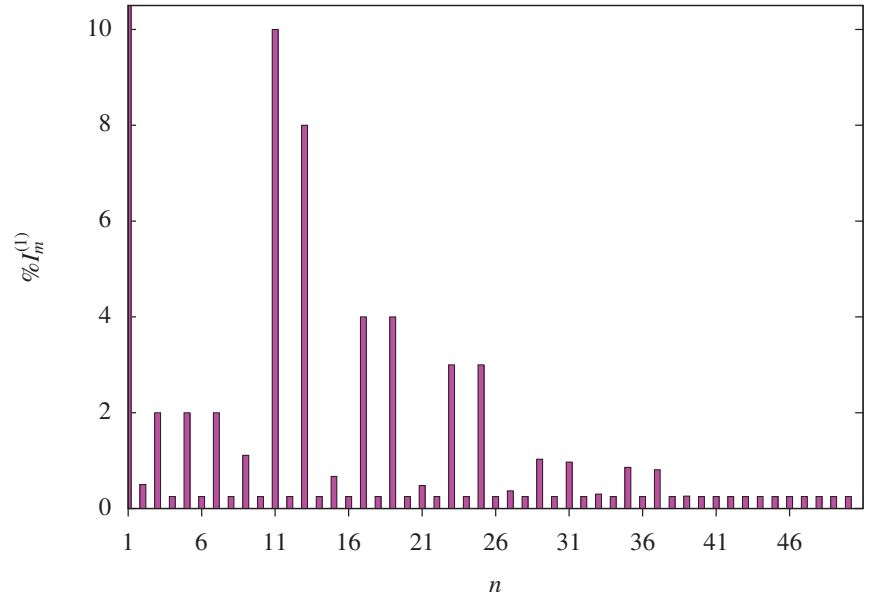

Figure 3. The limits for the harmonic content of the rectifier input currents

this rectifier is by nature a three-level converter which results in reduced input filtering inductance value for the same peak to peak ripple value with respect to the Boost case.

The control strategies for all three analyzed topologies are based on the development of the corresponding dq models and applying a conventional PI controller to the faster inner current loop and a PI controller for the slower output voltage loop.

\section{Design ImpaCt of the Relevant Avionics REGULATIONS}

The avionic equipment needs to successfully pass severe testing requirements before it can be considered as a candidate for future on-board use. Commonly, the main standard for airplane equipment is DO-160 F [16]. In this standard a wide spectrum of tests in harsh environmental conditions are defined and three of these are highlighted in this Section due to their impact in the rectifier design: Input Currents Spectrum Quality test, Input Three-phase Voltage Generator Unbalance test and Input Generator THDV test. The procedures are taken from DO-160 F sections: 16.7.1.2, 16.5.1.1.c.1 and 16.5.1.8.2 respectively. All of these tests are performed at 360, 400 and $800 \mathrm{~Hz}$. Moreover, a failure analysis is briefly addressed and discussed.

\section{A. Input Current Spectrum Quality}

The input current harmonic content test is done with the rectifier operating at full load. Moreover, the input generator provides balanced three-phase voltages. The test is passed if current harmonics on all three phases are below limits given in Figure 3, $P F$ per phase remains above 0.8 lagging and 0.95 leading and power difference between any of the two phases remains below 590 VA.

\section{B. Input Three-phase Voltage Generator Unbalance}

The second test used to measure performance of the rectifier is regarded to the potential operation under unbalance in the generator voltage amplitudes and/or relative phase shift differences. The phase voltages are accordingly unbalanced both in phase and amplitude and applied to the rectifier operating at nominal power level. The test is passed if $P F$ per phase remains above 0.8 lagging and 0.95 leading and power difference between any of the two phases remains below 590 VA. 


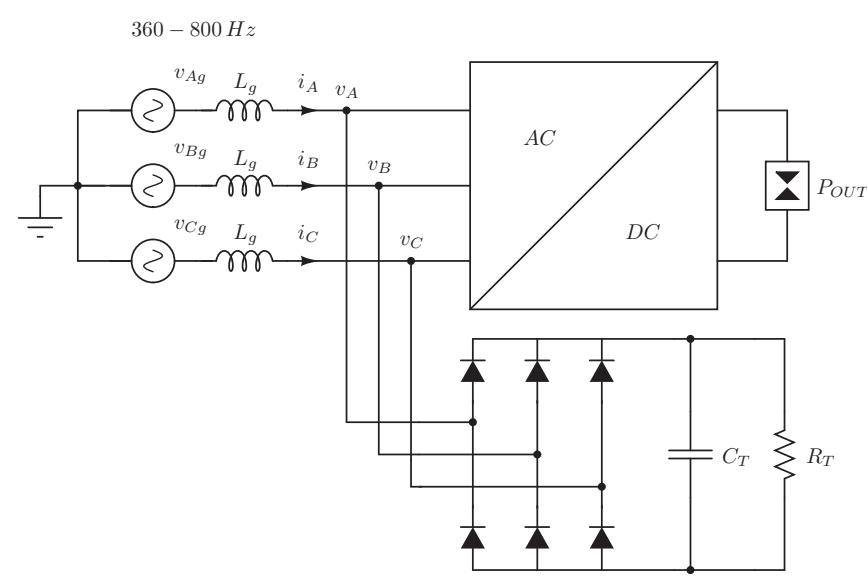

Figure 4. The circuit setup for the THDV test

\section{Input Generator THDV}

In this test setup, a three-phase six-pulse rectifier is connected at the point of common coupling as shown in Figure 4 , where $L_{\mathrm{g}}$ is the generator output impedance. The $C_{\mathrm{T}}$ and $R_{\mathrm{T}}$ load is then varied until a THD in voltage of $10 \%$ is achieved in the points $v_{\mathrm{A}}, v_{\mathrm{B}}$ and $v_{\mathrm{C}}$. Afterwards, the rectifier is connected in parallel with the six-pulse bridge and the test is passed if the THD in above-mentioned voltages does not surpass $12 \%$ at full load. This test particularly penalized the volume of the output capacitor of the Buck rectifier since a slow inner current and outer output voltage loop were needed in order to pass the test.

The main source of the issue of the Buck rectifier lies in the fact that the modulation used to drive the rectifier from [11] is meant to be used with the balanced, harmonic free input voltages. Therefore, it becomes the source of additional harmonic content in the input currents drawn by the rectifier which, as a consequence, additionally distorts input voltages at the point of common coupling. This issue can be alleviated at the modulation level by developing different modulation scheme or at higher level of abstraction such as control level.

$$
\omega_{\mathrm{BW}}>\frac{1}{R_{\mathrm{OUT}} C_{\mathrm{OUT}}}
$$

At the control level the generated input current harmonics can be treated as a disturbance in the current in the $d$ axis of the dq domain. Fast reaction to it by the controller would provoke additional harmonic content drawn by the rectifier due to the used modulation strategy. Thus, reduction of the bandwidth of the inner current loop provides an opportunity to reduce the impact of the present harmonics, since slow loop basically acts as current filter.

Slowed down current loop implies reduction of bandwidth of the output voltage loop. However, as shown in [17] for the constant power load case, there exists minimum bandwidth of the output voltage loop for which stability is assured. Therefore, for a given fixed value of the negative dynamic resistance given by the output power level, reduction of the bandwidth of the output voltage loop implies increase of the output capacitance value in a proportional manner as given by 1. Similar analysis can be applied to the other two candidates.

\section{Robustness to Failures}

Since the analyzed rectifier is a potential candidate for future use in the aircraft, a thorough failure analysis of the
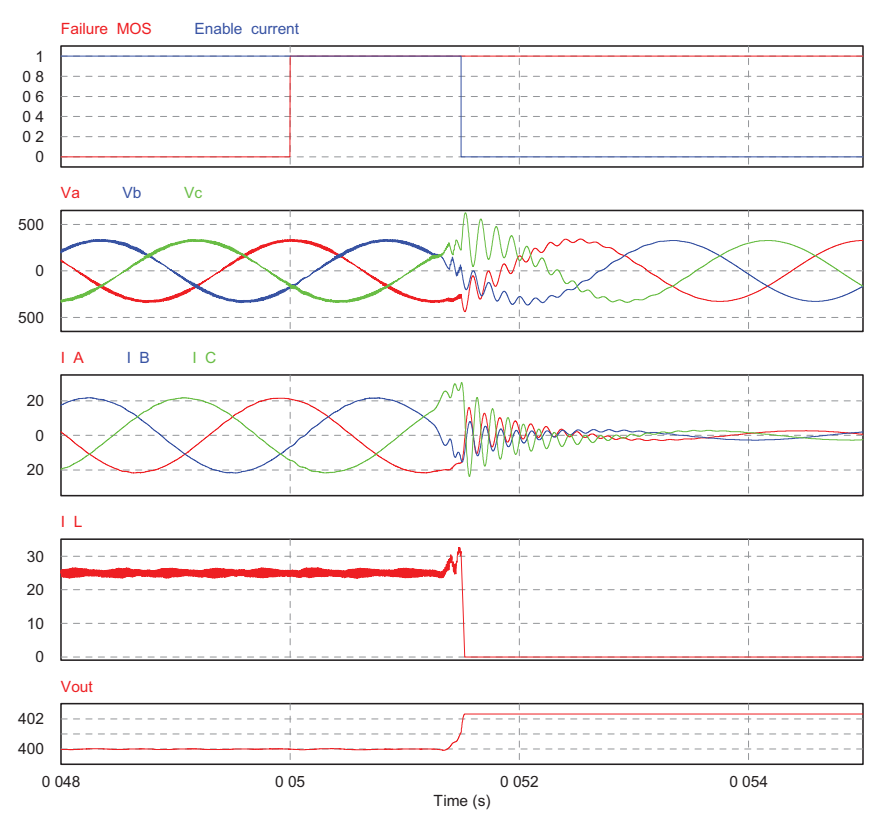

Figure 5. Failure of one MOSFET as a short circuit in the Buck rectifier

power stage needs to be addressed accordingly. If a critical failure is identified, in the sense in which it would yield to destruction of other parts of the system, additional circuitry must be added in order to detect each failure and prevent accumulative damage to the rectifier.

The failure that is applied to the rectifier is a single component failure. The analyzed cases include: short-circuit of any MOSFET (SCMOS), short-circuit of any high frequency diode (SCDHF), short-circuit of the free-wheeling diode (SCDHF), open circuit of any MOSFET (OCMOS), open circuit of any high frequency diode (OCDHF) open circuit of the free-wheeling diode (OCDFW), short circuit of one phase to the ground (SCPHGND), short circuit between phases (SCPHPH), short circuit of one side of the DC link to ground (SCDC+GND and SCDC-GND) etc. In the case of the Buck rectifier the added circuitry is sensing of input generator currents since short circuit of a MOSFET proved to be a failure detected faster with input current measurement. Any other failure would be detected and contained with the measurements already needed for the operation of the rectifier. An overview of detection of failures is presented for the Buck rectifier in Table I. The Table shows the signals where a failure can be detected.

For the Vienna rectifier, due to the increased number of components, additional failure modes are included such as short-circuit or open circuit of a low frequency diode (SCLFD and OCLFD) and open circuit of a main relay (OCREL) while the failures of the free-wheeling diode are excluded. In order for it not to provoke high inrush currents, a set of three-

Table I

FAILURE DETECTION OF THE BUCK RECTIFIER

\begin{tabular}{cccc}
\hline Signal to be Measured & Input Voltage & Input Current & Output Voltage \\
\hline \multirow{5}{*}{ Failures Detected } & SCPHPH & SCPHPH & SCPHPH \\
& SCDFW & SCPHGND & SCPHGND \\
& SCDHF & SCDFW & OCDFW \\
& SCDC+GND & SCDHF & OCDHF \\
& SCDC-GND & SCMOS & OCMOS \\
\hline
\end{tabular}


phase relays for the start-up sequence is necessary. Apart from that, when a failure SCDC+GND or SCDC-GND occurs, the rectifier needs to be disconnected from the grid due to the sudden series connection of a voltage source, an inductor and a diode. Therefore, it is necessary to add an additional threephase relay $\left(S_{A s s}, S_{B s s}, S_{C s s}\right)$ for this failure mode. These relays can be seen at the input of the rectifier in Figure 2. The rest of the failures analyzed could be detected and contained with the already included measurements. Apart from the OCLFD and SCDC+GND (SCDC-GND) failures, all could be detected only with the input voltage measurement. The OCLFD failure is detected with output voltage measurement, while the SCDC+GND and SCDC-GND failures are detected with input voltage and current sensors.

An example of a one-component failure of the Buck rectifier is presented in Figure 5. The MOSFET fails as a short circuit at a time instant of $50 \mathrm{~ms}$ and, as a consequence, input generator currents start to increase until an over-current protection is activated at the input. After the activation of the protection, all MOSFETs are commanded to open and thus the active power flow is intercepted. The rectifier continues to draw reactive currents due to the EMI filtering capacitors.

\section{Comparison of the Power Stages}

Since all analyzed rectifiers are designed to pass tests based on the simulations defined in the previous Section and to be robust to certain failure scenarios, the comparison of the power stages will be addressed in this Section.

For the avionic applications the employed semiconductors maximum instantaneous blocking voltage that can appear must be limited to $70 \%$ of the rated voltage. Moreover, the maximum junction temperature must be limited to $75 \%$ of the maximum allowed semiconductor junction temperature. Similarly, the maximum temperature of the ferromagnetic cores used for the employed magnetic components must be limited to $75 \%$ of the maximum allowed operating temperature defined by the corresponding manufacturer. All analyzed rectifiers have the switching frequency fixed at $100 \mathrm{kHz}$.

In Table II are shown the breakdown of losses and total efficiency at nominal power. The volume presented in this Table is the sum of volumes of reactive components such are capacitors and inductors, while the weight considers only the inductive elements since their weight represent the largest portion of the total weight apart from the heatsink.

The weight of the inductors was expected to be the lowest in the case of the Buck rectifier due to the fact that the filtering inductors are located at the DC side of the rectifier. Comparing the weight of the inductors in Vienna and Boost rectifier, the three-level nature of the Vienna rectifier shows advantages with respect to the two-level Boost rectifier in terms of reduced weight while maintaining the same peak to peak current ripple. Also, the core losses are significantly lower in the case of the Buck rectifier due to the absence of large low frequency flux component in the core.

Regarding the volume of the reactive components, the largest part is related to the DC link capacitors and EMI filtering capacitors. Unlike the Boost and the Vienna rectifier, the Buck rectifier has suffered from several redesigns in order to meet with the tests defined in the previous Section and the main element that had to be increased was output DC link capacitor to $300 \%$ of the initial value in order to pass the THDV test. Moreover, due to the absence of the inductors on the $\mathrm{AC}$ side in case of the Buck rectifier, a higher capacitor values are required in order for the Buck to meet with the input current harmonic requirements.

The dominant part of the losses in all three analyzed rectifiers lies in the semiconductor losses. Since the Buck rectifier has the least number of hard commutations per switching cycle, it is sensible to expect that it will exhibit the highest efficiency. Moreover, losses in the magnetic components are lower in the case of the Buck rectifier due to abscence of the large AC fundamental like in the Boost or Vienna case. Therefore, lower core losses are present in the Buck case with respect to the other two solutions.

The minimum output power at which the topology can provide unity displacement power factor has some limitations. In the case of the Buck rectifier the limit comes from the reduced space vector combinations of the unidirectional topology, while in the Vienna rectifier the limit is observed due to the start of Discontinuous Conduction Mode operation at lighter loads. In the Boost case, due to its bidirectional nature, there is no limit in the space vector combinations and thus large amount of the reactive power can be absorbed by that topology. The limit is the highest for the Buck rectifier, followed by the Vienna rectifier and the Boost rectifier at $30 \%, 25 \%$ and $0 \%$ of $P_{\text {OUT }}$ respectively.

Reflecting on the start-up procedure, in the case of the Boost derived topologies an additional circuit is needed in order to avoid high inrush currents due to the need for precharge of the output capacitor to the maximum line to line voltage and thus blocking the diode bridge conduction. That additional circuitry effectively reduces the reliability of the whole system.

Lastly, the driving complexity of the MOSFETs is lowest in the case of the Boost rectifier, moderate in the case of the Buck rectifier, and highest in the case of the Vienna rectifier. The complexity of the Vienna case, however, can be reduced applying modulation proposed by [14] and virtually reducing it to the SPWM modulation.

\section{VAlidation of the Results}

In order to validate the theoretical analysis, a $10 \mathrm{~kW}$ prototype has been manufactured presented in Figure 19. The rectifier along with the DC/DC converter which will be

Table II

BREAKDOWN OF LOSSES, WEIGHT AND VOLUME COMPARISON

\begin{tabular}{|c|c|c|c|c|c|c|c|c|c|c|c|c|c|c|}
\hline \multirow[t]{2}{*}{ Topology } & \multicolumn{2}{|c|}{$P_{\mathrm{MOS}}[\mathrm{W}]$} & \multicolumn{2}{|c|}{$P_{\mathrm{HFD}}[\mathrm{W}]$} & \multicolumn{2}{|c|}{$P_{\mathrm{FWD}}[\mathrm{W}]$} & \multirow[t]{2}{*}{$P_{\mathrm{LFD}}[\mathrm{W}]$} & \multicolumn{2}{|c|}{$P_{\mathrm{L}}[\mathrm{W}]$} & \multirow[t]{2}{*}{$P_{\mathrm{RD}}[\mathrm{W}]$} & \multirow[t]{2}{*}{$P_{\text {тот }}[\mathrm{W}]$} & \multirow[t]{2}{*}{$V\left[\mathrm{dm}^{3}\right]$} & \multirow[t]{2}{*}{$m[\mathrm{~kg}]$} & \multirow[t]{2}{*}{$\eta[\%]$} \\
\hline & SW & CND & SW & CND & SW & CND & & $\mathrm{Cu}$ & $\mathrm{Fe}$ & & & & & \\
\hline Boost & $6 \times 39$ & $6 \times 0.7$ & $\approx 0$ & $6 \times 7$ & - & - & - & $3 \times 4$ & $3 \times 11$ & - & 325.2 & 0.65 & 1.5 & 96.8 \\
\hline Buck & $12 \times 5.5$ & $12 \times 3.2$ & $\approx 0$ & $12 \times 6.8$ & $\approx 0$ & $4 \times 6$ & - & $2 \times 3$ & $2 \times 2$ & $3 \times 5.2$ & 235.6 & 1.04 & 1.2 & 97.5 \\
\hline Vienna & $6 \times 11.5$ & $6 \times 9.7$ & $\approx 0$ & $6 \times 6.25$ & - & - & $6 \times 5$ & $3 \times 6$ & $3 \times 6$ & $3 \times 0.25$ & 231.5 & 0.60 & 1.0 & 97.7 \\
\hline
\end{tabular}




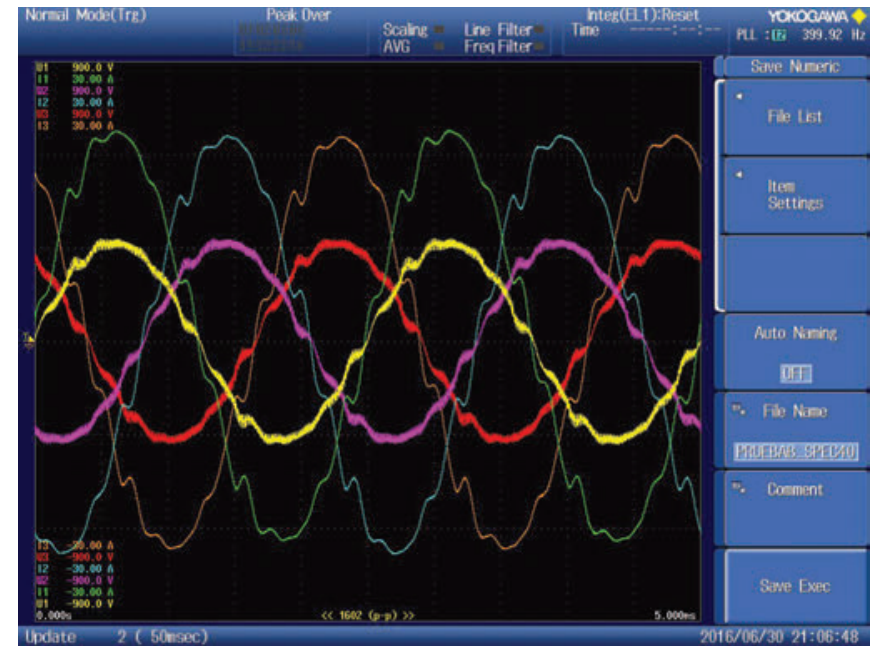

Figure 6. Input voltages and currents at $400 \mathrm{~Hz}$ with $L_{g}=300 \mu \mathrm{H}$

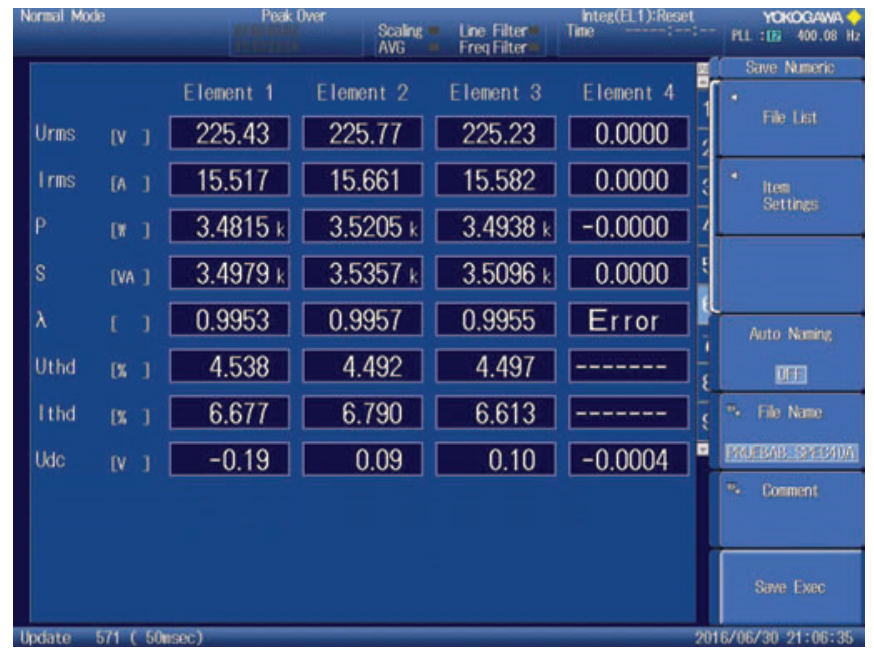

Figure 9. Input power quality at $400 \mathrm{~Hz}$ with $L_{g}=300 \mu \mathrm{H}$

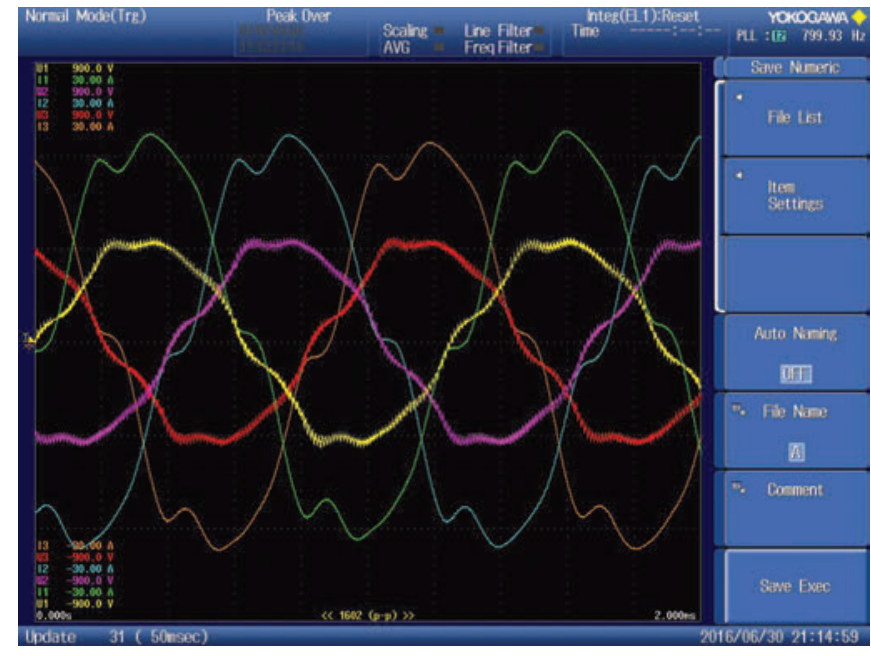

Figure 7. Input voltages and currents at $800 \mathrm{~Hz}$ with $L_{g}=300 \mu \mathrm{H}$

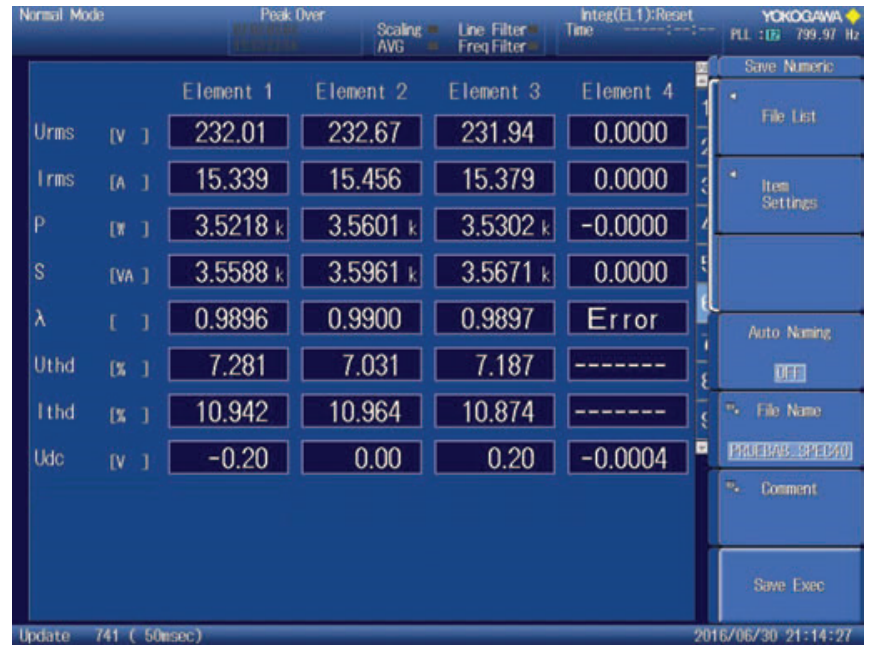

Figure 10. Input power quality at $800 \mathrm{~Hz}$ with $L_{g}=300 \mu \mathrm{H}$

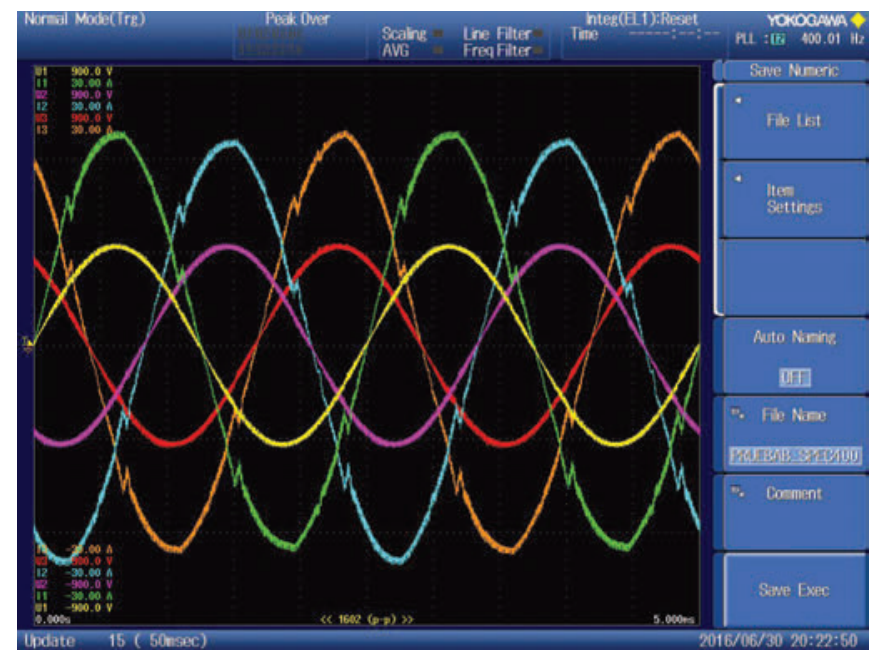

Figure 8. Input voltages and currents at $400 \mathrm{~Hz}$ without $L_{g}$

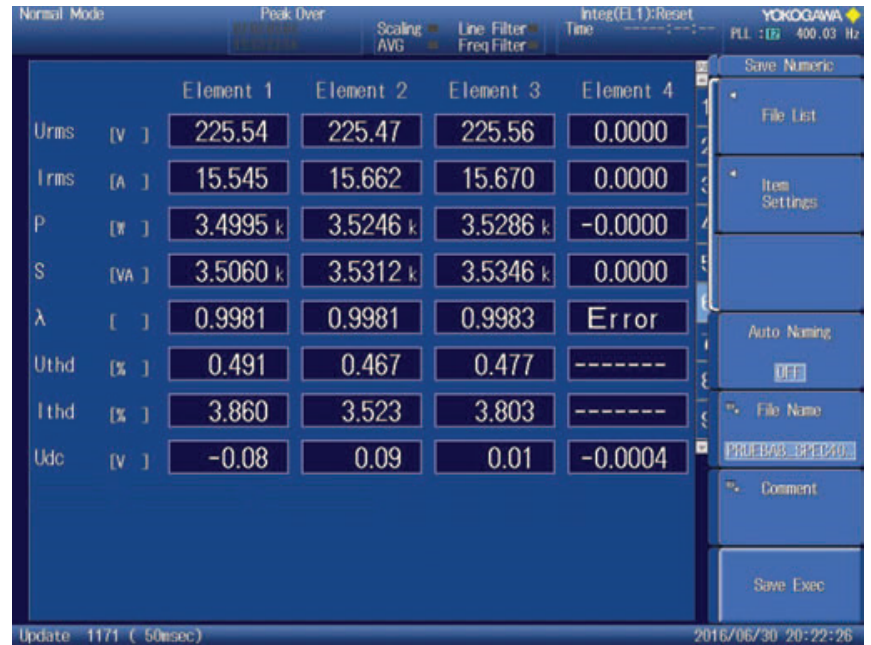

Figure 11. Input power quality at $400 \mathrm{~Hz}$ without $L_{g}$ 


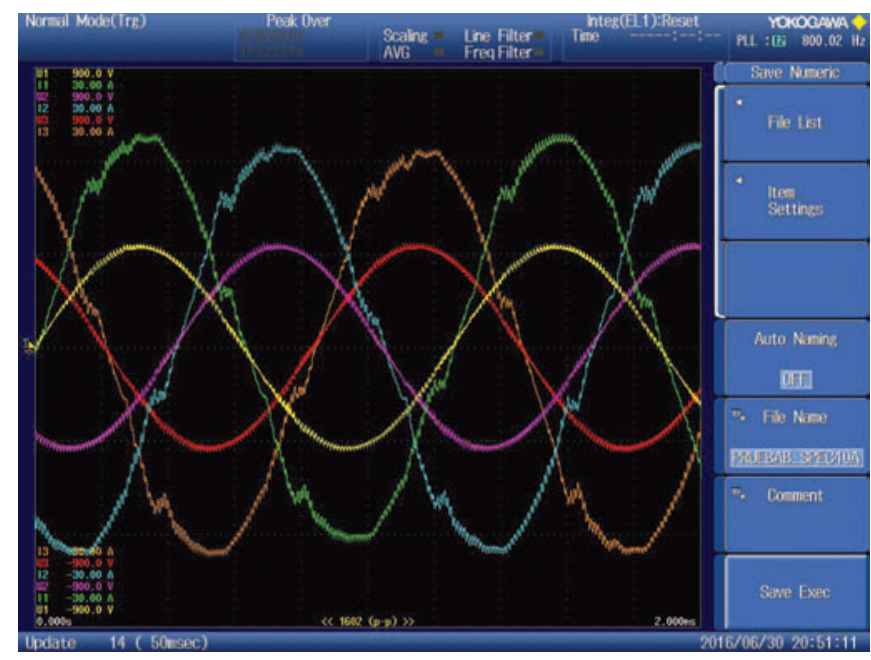

Figure 12. Input voltages and currents at $800 \mathrm{~Hz}$ without $L_{g}$

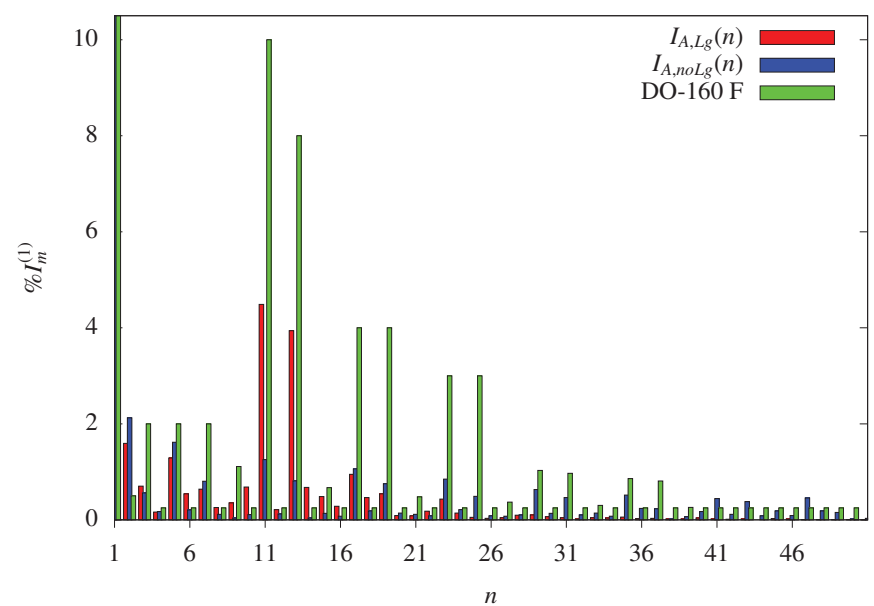

Figure 13. Input currents spectrum comparison at $400 \mathrm{~Hz}$ with and without $L_{g}$

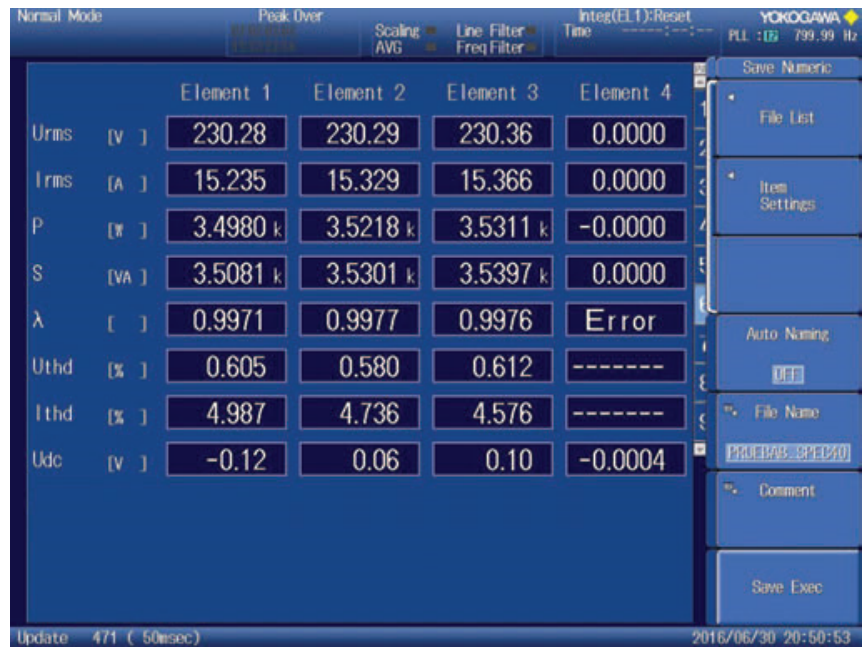

Figure 15. Input power quality at $800 \mathrm{~Hz}$ without $L_{g}$

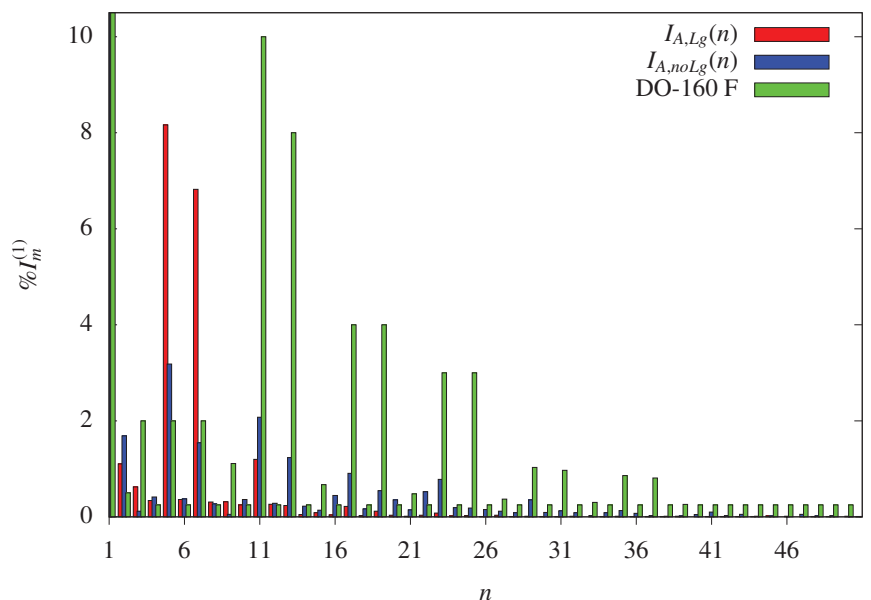

Figure 16. Input currents spectrum comparison at $800 \mathrm{~Hz}$ with and without $L_{g}$

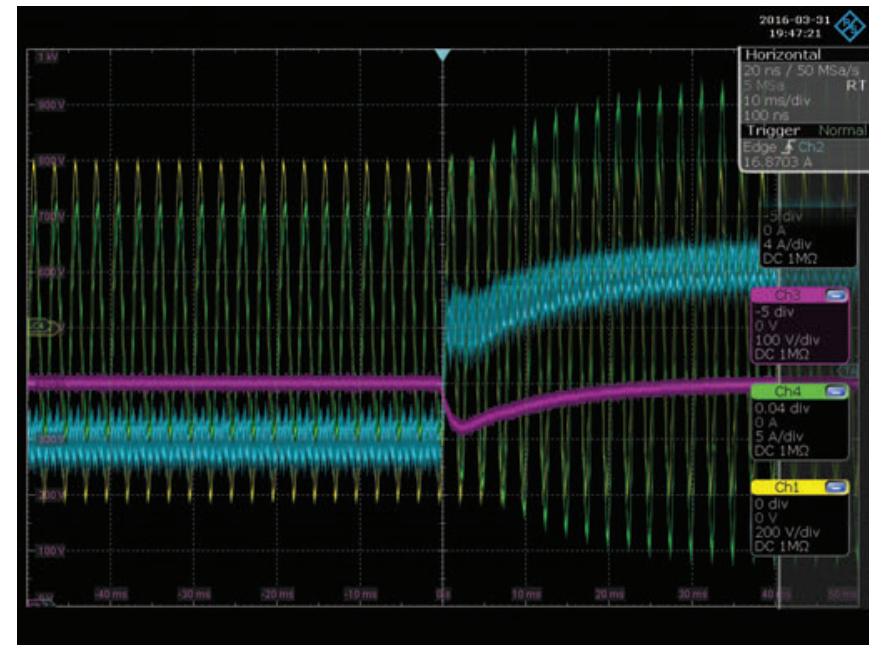

Figure 14. Resistive step up from $5 \mathrm{~kW}$ to $10 \mathrm{~kW}$ at $400 \mathrm{~Hz}$

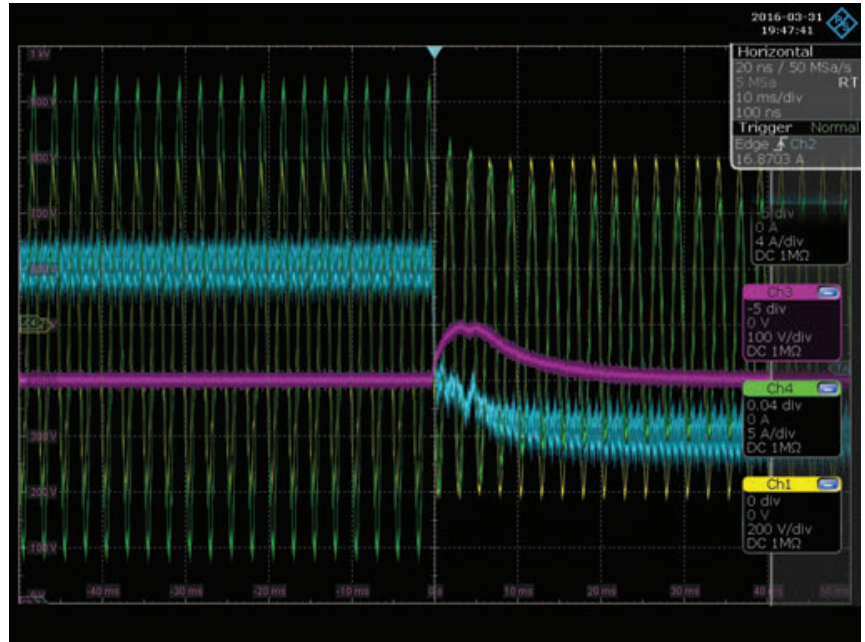

Figure 17. Resistive step down from $10 \mathrm{~kW}$ to $5 \mathrm{~kW}$ at $400 \mathrm{~Hz}$ 


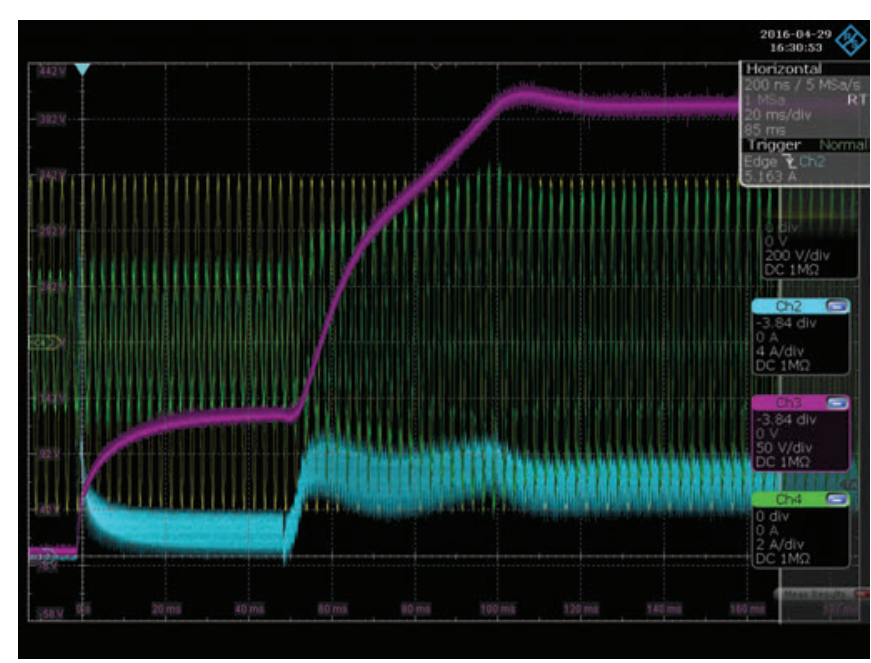

Figure 18. The rectifier start-up with light load at $400 \mathrm{~Hz}$

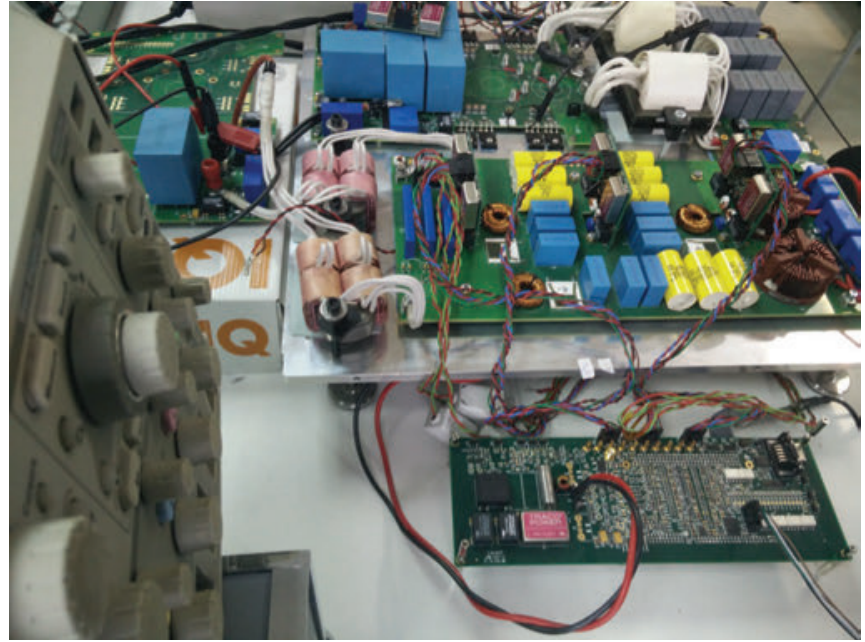

Figure 19. Experimental setup connected at the output is presented in Figure 19. The part of the rectifier is located in the lower section of the heatsink. The EMI filter board is located on top of the MOSFETs which are directly mounted onto the aluminum base PCB. A trade-off has been made between ease of the thermal management on one hand and minimization of the parasitic inductances of the traces interconnecting power stage with the EMI capacitors on the other hand.

The experimental results supplying approximately $10 \mathrm{~kW}$ are presented in Figures 6-18. The results show higher presence of harmonics in the current spectrum than the ones from the simulation. One of the reasons is explained in [18] is due to the overlapping time. In this case, the reduction of the overlapping time has not yielded to sufficient mitigation of the harmonics below 7th, which is where the main problem lies especially for the $800 \mathrm{~Hz}$ case. The authors suspect that the reason of the increased harmonic content lies in the interaction between high output impedance of the generator and the input impedance of the rectifier. The efficiency of the rectifier at nominal power is around $96.3 \%$ and $95.8 \%$ for 400 and 800 $\mathrm{Hz}$ respectively.

In order to have better insight in the harmonic content generated by the rectifier, the EMI filter resonance has been pushed to high frequencies by removing the input inductors and the result is presented in Figures 8-16. It can be seen that harmonics below 13th increase with increasing the grid frequency. The reason at the present moment is unknown.

The performance of the control loops implemented in the DSP F28335 is shown in Figures 14-18. The control consists in the faster inner DC link inductor current loop closed at 300 $\mathrm{Hz}$, and the slower outer voltage loop closed at $30 \mathrm{~Hz}$. The yellow trace is denoting input line to line voltage $v_{A B}$, the cyan trace denotes DC link inductor current $i_{L}$, the magenta trace denotes output DC link voltage $v_{O U T}$ and the green trace denotes input current in the first phase $i_{A}$.

Figure 18 shows the start-up procedure. First the rectifier PLL gets synchronized to the grid in several tens of milliseconds, then it closes both control loops and ramps up the voltage in $100 \mathrm{~ms}$ to the nominal value of $400 \mathrm{~V}$. The initial peak of the current of $20 \mathrm{~A}$ is happening due to the sensors relatively large error at values far from nominal ones (25 A and $400 \mathrm{~V}$ ). Thus, the error is generated in the control loops which is provoking the initial peak. At the start-up, the rectifier was supplied with a load of $1.5 \mathrm{~kW}$.

\section{CONCLUSION}

This paper discusses and compares three different active rectifiers for aircraft applications.

- The Boost rectifier: Has the simplest design and complexity, however its major drawback lies in the susceptibility to the shoot-through failure and the need for the start-up circuitry. Finally, any test from the DO-160 F was not severely penalizing the design.

- The Buck rectifier: Has more complex design than the Boost, however its major advantage over the other two reflects in better handling of failure scenarios. Main drawback lies in increment of the reactive components total volume of $70 \%$ due to the need to increase the output capacitance $300 \%$ in order to comply with the THDV test.

- The Vienna rectifier: Out of the three analyzed topologies, overall conventional metrics such as volume, weight and efficiency are all in the favor of the Vienna rectifier. However, higher complexity and need for the additional start-up circuitry reflected in higher number of failure modes and thus diminished the robustness. Moreover, the volume of the additional start-up circuitry is not included in the volume presented in the Table II and by doing so it would further reduce the volume difference between the Vienna and the Buck rectifier. Lastly, like in the Boost case, any test from the DO-160 F was not severely penalizing the design.

From the theoretical point of view, both the Vienna and the Buck rectifier proved to be an interesting solution to be utilized in avionic applications. If the rectifier was to be analyzed as an standalone unit, then the Vienna rectifier would have been chosen. However, for the particular specifications of this project and due to the fact that the Vienna needs to boost the voltage of the DC link to around $800 \mathrm{~V}$, that choice would severely complicate and penalize the design of the DC/DC converter transformer with turns ratio of approximately 30:1. Therefore, the authors choose the Buck rectifier as a more appropriate solution regarding the trade-off between efficiency, weight, safety and complexity of the next stage. 
Even though the Buck rectifier presents good characteristics at the simulation level, practical results had shown high level of low frequency harmonics which need to be improved in order for it to be a valid candidate for the future applications in the aircraft where requirements from the Section III-A have to be met. The authors think that the reason of the increased harmonic content lies in the interaction between high output impedance of the generator and the input impedance of the rectifier and it requires further research.

\section{REFERENCES}

[1] S. Choi, A. Von Jouanne, P. Enjeti, and I. Pitel, "Polyphase transformer arrangements with reduced kva capacities for harmonic current reduction in rectifier type utility interface," in Power Electronics Specialists Conference, 1995. PESC '95 Record., 26th Annual IEEE, vol. 1, Jun 1995, pp. 353-359 vol.1.

[2] M. Ivkovic, P. Pejovic, and Z. Janda, "Application of optimal and suboptimal current injection in twelve-pulse three-phase diode rectifiers," in Power Electronics Specialists Conference, 2008. PESC 2008. IEEE, June 2008, pp. 3143-3149.

[3] D. Cucak, P. Pejovic, and J. Kolar, "Experimental analysis of the lineside interphase transformer magnetizing currents in three-phase output voltage type rectifiers," Electronics 01/2010, 2010.

[4] K. Mino, G. Gong, and J. Kolar, "Novel hybrid 12-pulse line interphase transformer boost-type rectifier with controlled output voltage," in Power Electronics and Motion Control Conference, 2004. IPEMC 2004. The 4th International, vol. 2, Aug 2004, pp. 924-931 Vol.2.

[5] G. Gong, M. Heldwein, U. Drofenik, J. Minibock, K. Mino, and J. Kolar, "Comparative evaluation of three-phase high-power-factor acdc converter concepts for application in future more electric aircraft," Industrial Electronics, IEEE Transactions on, vol. 52, no. 3, pp. 727737, June 2005.

[6] S. Hiti, "Modeling and control of three-phase pwm converters," $\mathrm{Ph} . \mathrm{D}$. dissertation, Virginia Polytechinc Institute and State University, 1995.

[7] S. Hiti, D. Boroyevich, and C. Cuadros, "Small-signal modeling and control of three-phase pwm converters," in Industry Applications Society Annual Meeting, 1994., Conference Record of the 1994 IEEE, Oct 1994, pp. 1143-1150 vol.2.
[8] S. Hiti, D. Borojevic, R. Ambatipudi, R. Zhang, and Y. Jiang, "Average current control of three-phase pwm boost rectifier," in Power Electronics Specialists Conference, 1995. PESC '95 Record., 26th Annual IEEE, vol. 1, Jun 1995, pp. 131-137 vol.1.

[9] J. Muhlethaler, M. Schweizer, R. Blattmann, J. Kolar, and A. Ecklebe, "Optimal design of lcl harmonic filters for three-phase pfc rectifiers," in IECON 2011 - 37th Annual Conference on IEEE Industrial Electronics Society, Nov 2011, pp. 1503-1510.

[10] S. Hiti, V. Vlatkovic, D. Borojevic, and F. Lee, "A new control algorithm for three-phase pwm buck rectifier with input displacement factor compensation," in Power Electronics Specialists Conference, 1993. PESC '93 Record., 24th Annual IEEE, Jun 1993, pp. 648-654.

[11] T. Nussbaumer and J. Kolar, "Advanced modulation scheme for threephase three-switch buck-type pwm rectifier preventing mains curren distortion originating from sliding input filter capacitor voltage intersections," in Power Electronics Specialist Conference, 2003. PESC '03. 2003 IEEE 34th Annual, vol. 3, June 2003, pp. 1086-1091 vol.3.

[12] T. Nussbaumer, M. Baumann, and J. Kolar, "Comprehensive design of a three-phase three-switch buck-type pwm rectifier," Power Electronics, IEEE Transactions on, vol. 22, no. 2, pp. 551-562, March 2007.

[13] R. Burgos, R. Lai, S. Rosado, F. Wang, D. Boroyevich, and J. Pou, "A full frequency range average model for vienna-type rectifiers," in Power Electronics Specialists Conference, 2008. PESC 2008. IEEE, June 2008, pp. 4495-4502.

[14] M. Hartmann, "Ultra-compact and ultra-efficient three-phase pwm rectifier systems for more electric aircraft," Ph.D. dissertation, ETH Zurich, 2011.

[15] R. Lai, F. Wang, R. Burgos, D. Boroyevich, D. Jiang, and D. Zhang, "Average modeling and control design for vienna-type rectifiers considering the dc-link voltage balance," Power Electronics, IEEE Transactions on, vol. 24, no. 11, pp. 2509-2522, Nov 2009.

[16] I. RTCA, "Environmental conditions and test procedures for airborne equipment," RTCA, Inc, Tech. Rep., 2007.

[17] S. Zhao, J. Molina, M. Silva, J. Oliver, P. Alou, J. Torres, F. Arevalo, O. Garcia, and J. Cobos, "Design of energy control method for threephase buck-type rectifier with very demanding load steps to achieve smooth input currents," Power Electronics, IEEE Transactions on, vol. 31, no. 4, pp. 3217-3226, April 2016

[18] B. Guo, F. Xu, Z. Zhang, Z. Xu, F. Wang, L. M. Tolbert, and B. J. Blalock, "Compensation of input current distortion in three-phase buck rectifiers," in Applied Power Electronics Conference and Exposition (APEC), 2013 Twenty-Eighth Annual IEEE, March 2013, pp. 930-938. 